\title{
Are there differences in practice depending on the instrument played?
}

\author{
Susan Hallam, Maria Varvarigou, Andrea Creech, Ioulia Papageorgi
}

\begin{abstract}
There has been little research on instrument differences in the length and nature of instrumental practice or how these may interact with level of expertise. This paper aimed to address this issue. 3325 young people ranging in level of expertise from beginner to the level required for entry to higher education conservatoire completed a questionnaire which consisted of a number of statements relating to time spent practising, practising strategies, organisation of practice, and motivation to practice with a seven-point rating scale. Data were analysed in relation to nine levels of expertise. Factor analysis revealed seven factors which were used to make comparisons between those playing different classical instruments. The findings showed that those playing keyboard instruments practised the most followed by strings, brass and woodwind. There were relatively few statistically significant instrument differences in practice strategies. Where there were differences it was the woodwind players who tended to adopt less effective strategies. There were some interactions between level of expertise and practice which generally showed no clear patterns suggesting complexity in the development of musical expertise in relation to different instruments. The findings are discussed in terms of possible reasons for these differences.
\end{abstract}

\section{Introduction}

Research on practising has a long history. The first research was undertaken in the 1940s by Rubin-Rabson, (e.g. 1940; 1941) who explored, through a series of experiments, which practice strategies were the most effective. Since then hundreds of studies have been 
undertaken. These have mainly focused on the time spent practising and its impact on the level and quality of musical outcomes and the quality of the practice itself and how to improve it (for a recent review see Jørgensen and Hallam, 2016). There has been very little research on instrument differences in time spent practising and the practice strategies adopted. This research addresses this issue by reanalysing data from a factor analytic study which focused on issues relating to changes in individual practice in young people as they developed instrumental expertise (Hallam et al., 2012). The current paper reanalyses the data to enable comparisons to be made of the practising strategies adopted by those playing different instruments and the time spent practising. The original paper was based on data from 3,325 children ranging in level of expertise from beginner through to grade 8 level (the minimum required for conservatoire entrance in the UK). Participants completed a questionnaire which consisted of statements relating to practising strategies, organization of practice, concentration and attitudes towards practising using a seven-point Likert rating scale. Data were analyzed in relation to nine levels of expertise. Factor analysis revealed seven factors relating to practice itself: the adoption of systematic practice strategies; the organization of practice; the use of recordings for listening and feedback and use of the metronome; the use of analytic strategies; the adoption of ineffective strategies; concentration; and the immediate correction of errors. There were statistically significant linear relationships between level of expertise and the adoption of systematic practice strategies; use of recordings for listening and feedback and use of the metronome; the adoption of ineffective strategies; and immediate correction of errors but not for organization of practice; use of analytic strategies; and concentration. The data on attitudes towards practice showed that students enjoyed practice less the more advanced they became. The research reported here extends that research exploring instrument differences in approaches to practising. 
Few studies have been undertaken which have examined differences in practice between instruments. An exception to this is the work of Jørgensen $(1997,2002)$ who studied differences in time spent practising in conservatoire students. He collected data from a population of 182 students who were all completing a four year undergraduate programme at the Norges musikkhogskile. They were enrolled in one of four programmes: instrumental, vocal, church music or music education. One hundred and forty one students returned a completed questionnaire representing each of the different undergraduate programmes and the four study years. Eighty four percent of female students responded and $72 \%$ of male students. The questionnaire differentiated between solitary practice and practice with others. Students were asked to base their estimates of practice on a typical study week. Eighty five percent of the students reported practising on 6 or 7 days each week and there was a mean daily practice time of 2 hours 40 minutes. Twelve percent of the students practised on average for one hour or less on the days that they practised, $11 \%$ for four hours or more. The average weekly practice time was 17 hours. Eight percent of the students practised for five hours or less while five percent practised for more than 30 hours. The pianists practised the most doing about 32 hours 45 minutes practice each week followed by the string players who did on average 28 hours 10 minutes each week The brass and woodwind players did considerably less practice, 18 hours 50 minutes and 18 hours 10 minutes respectively. However, there was wide variation, for instance amongst the brass players from 570 minutes to 1131 , for the pianists 450 to 1323 minutes, strings, 840 to 1690 minutes and woodwind 420 to 1088 minutes. There were also differences within each group, for instance, in the string group it was the violinists who did the most practice, in the woodwind the oboists and in the brass, the tuba players (see Table 1). 
Table 1: Instrument differences in time spent practising by Norwegian conservatoire students (Jørgensen, 2002)

\begin{tabular}{|c|c|c|c|c|c|c|}
\hline Instrument & $\mathbf{N}$ & $\begin{array}{l}\text { minimum } \\
\text { minutes }\end{array}$ & $\begin{array}{l}\text { Mean } \\
\text { Minutes }\end{array}$ & $\begin{array}{l}\text { maximum } \\
\text { minutes }\end{array}$ & $\begin{array}{l}\text { hours } \\
\text { mean }\end{array}$ & $\begin{array}{l}\text { SD } \\
\text { minutes }\end{array}$ \\
\hline \multicolumn{7}{|c|}{ Strings } \\
\hline Violin & 8 & 1170 & 1900 & 2760 & $31^{\prime} 40$ & 537 \\
\hline Double bass & 3 & 1110 & 1630 & 1980 & 27'10 & 375 \\
\hline Cello & 7 & 1080 & 1594 & 2040 & $26 ’ 35$ & 368 \\
\hline Viola & 7 & 840 & 1570 & 2340 & $26^{\prime} 10$ & 526 \\
\hline \multicolumn{7}{|c|}{ Woodwind } \\
\hline Oboe & 2 & 1380 & 1545 & 1710 & $25^{\prime} 45$ & 165 \\
\hline Saxophone & 3 & 1260 & 1350 & 1470 & $22 ’ 30$ & 88 \\
\hline Flute & 8 & 450 & 1153 & 1920 & 19'15 & 558 \\
\hline Clarinet & 4 & 420 & 731 & 960 & $12 ’ 10$ & 230 \\
\hline \multicolumn{7}{|c|}{ Brass } \\
\hline Tuba & 2 & 960 & 1350 & 1740 & $22 ’ 30$ & 390 \\
\hline Horn & 5 & 840 & 1248 & 1710 & $20 ' 50$ & 279 \\
\hline Trumpet & 5 & 630 & 988 & 1290 & $16 ’ 30$ & 214 \\
\hline Trombone & 3 & 570 & 813 & 1170 & 13’35 & 258 \\
\hline \multicolumn{7}{|c|}{ Piano } \\
\hline Piano & 9 & 1620 & 1966 & 2460 & $32 ’ 45$ & 266 \\
\hline
\end{tabular}

Lammers and Kruger (2006) replicated Jorgensen's study with American and Japanese students using the same materials. Their focus was brass and woodwind students. The findings were similar with the brass students reporting carrying out 948 minutes practice each week in the USA and 1264 in Japan. The woodwind students reported 775 minutes practice in the USA and 783 in Japan. Jørgensen discussed these differences in terms of physiological restrictions related to the instrument's physical and technical demands and the nature and extent of the repertoire. The research reported here extends this work to a range of learners from beginner through to conservatoire level considering the amount of time spent practising and the range of practising strategies adopted.

The specific research questions were:

_ are there differences in the amount of weekly practice undertaken between young people playing different instruments? 
— are there differences in the practising strategies adopted by young people playing different instruments?

— are instrument differences consistent between those at novice and more advanced levels of expertise?

\section{Method}

\section{Design}

To ensure a large sample, the present study adopted a self-report questionnaire. The data were analysed using SPSS.

\section{Materials}

The questionnaire was devised based on the research literature and a smaller scale prior study (Hallam, 2013). The questionnaire sought information about the level of expertise attained (assessed by the highest examination grade achieved) and the quality of performance at that level of expertise (as measured by the mark obtained in the highest grade). In the UK there are several independent examination boards which offer graded instrumental examinations, usually from preliminary to grade 8 . Typically, graded examinations assess candidates' performance on pieces, scales, sight-reading, and aural tests, with some examination boards assessing technical exercises and improvisation tasks. These provide a convenient, widely recognised and impartial means of assessing level of expertise and through the mark given the quality of that expertise. Respondents were also asked to indicate the length of time they had spent learning to play an instrument and the number and length of practice sessions in a typical week. The questionnaire also included a range of statements relating to: the practising strategies adopted; the organization and management of practice; and motivation to practise. 
Respondents were requested to respond to these on a 7 point likert scale with 7 indicating the strongest agreement, 1 the strongest disagreement. The questionnaire was piloted on a small group of young musicians to ensure that the statements were easy to understand. Their feedback indicated that no changes were required. The full questionnaire is included in the appendix.

\section{Respondents}

Data were collected by a team of researchers from young people playing all of the classical and popular musical instruments in a variety of settings including two junior conservatoires, two Local Authority youth orchestras, two Local Authority Saturday Music schools, a conservatoire for popular music and three state comprehensive schools. The children who participated were receiving tuition on their instruments individually or in small groups of no more than four children. The organisations which the children were attending were approached and permission requested for questionnaires to be administered. Convenient times for the researchers to visit the organisations were negotiated.

A total of 3325 children ranging in level of expertise from beginner through to Grade 8 level (minimum required for conservatoire entrance in the UK) participated in the research. Of these 2027 (61\%) were girls 1225; (37\%) were boys with some not indicating their sex. The instruments that they played were representative of the classical and popular instruments played in the UK. The greatest number played the violin (28\%) followed by flute (10\%), piano $(10 \%)$, clarinet $(10 \%)$, cello $(8 \%)$, trumpet $(6 \%)$, viola $(3 \%)$, saxophone $(3 \%)$, French horn $(3 \%)$, trombone $(3 \%)$, oboe $(2 \%)$, double bass $(2 \%),(1 \%)$, tuba $(1 \%)$, bassoon $(1 \%)$, harp (1\%) with other instruments played by fewer than one percent of respondents. The age range was from 6 to 19 years and the number of months learning from 1 to 172 . The focus of 
this paper is the differences in those classed in different instrument groups. Of these 339 played piano, keyboard, organ or harp, 777 played woodwind instruments, 400 played brass instruments and 1043 played stringed instruments. Overall, data from 2559 learners were included in the comparisons.

\section{Procedure}

The research was designed taking account of the ethical guidelines of the British Psychological Society and the British Educational Research Association and was approved by the ethics committee of the Institute of Education, University of London. The organisations that the young people were attending were contacted and asked if they would be willing for the researchers to collect data from students. The young people themselves were told that they did not have to participate if they did not wish to do so and were assured that the data would remain confidential and that their parents and teachers would not have access to it. Informed consent from the young people was obtained as part of the questionnaire process. Parents were informed that the research was taking place and given the opportunity to withdraw their children.

The researchers administered the questionnaires to students in the various learning environments. The exact procedures for this varied depending on the environment. For instance, in schools, the children completed the questionnaires during music lessons, while in the extra-curricular environments questionnaires were distributed and collected during break periods between musical activities.

\section{Findings}

Are there differences in the amount of practice undertaken? 


\section{Time spent practising}

There were highly statistically significant differences in relation to the time spent practising by instrument group $(\mathrm{F}(3,2559=30.86, \mathrm{p}=.0001)$. Those playing piano, keyboard, organ and harp did the most practice followed by the strings, brass and woodwind (see Figure 1). There was also a statistically significant interaction between level of expertise and instrument group $(\mathrm{F}(3,24=1.81, \mathrm{p}=01)$ (see Table 2 and Figure 2). This shows that practice increases as expertise develops but that the time spent may vary during that process as a function of type of instrument played.

Table 2: Means of average weekly practice in minutes by level of expertise and instrument group

\begin{tabular}{|c|c|c|c|c|}
\hline \multicolumn{5}{|c|}{ Average weekly practice in minutes } \\
\hline Level of expertise & Instrument group & Mean & $\begin{array}{c}\text { Std. } \\
\text { Deviation }\end{array}$ & $\mathrm{N}$ \\
\hline \multirow{5}{*}{ Preliminary } & Piano, keyboard, organ, harp & 213.26 & 279.93 & 76 \\
\hline & Woodwind & 92.06 & 85.78 & 112 \\
\hline & Brass & 111.39 & 92.84 & 23 \\
\hline & Strings & 189.64 & 318.08 & 159 \\
\hline & Total & 160.09 & 253.94 & 370 \\
\hline \multirow{5}{*}{ Grade 1} & Piano, keyboard, organ, harp & 151.28 & 133.73 & 39 \\
\hline & Woodwind & 100.59 & 70.11 & 104 \\
\hline & Brass & 113.21 & 86.77 & 28 \\
\hline & Strings & 120.54 & 104.47 & 91 \\
\hline & Total & 116.41 & 96.82 & 262 \\
\hline \multirow{5}{*}{ Grade 2} & Piano, keyboard, organ, harp & 150.88 & 182.71 & 17 \\
\hline & Woodwind & 106.76 & 93.85 & 63 \\
\hline & Brass & 143.04 & 169.19 & 23 \\
\hline & Strings & 144.89 & 132.71 & 79 \\
\hline & Total & 132.02 & 131.84 & 182 \\
\hline \multirow{5}{*}{ Grade 3} & Piano, keyboard, organ, harp & 154.75 & 117.52 & 20 \\
\hline & Woodwind & 115.58 & 85.68 & 77 \\
\hline & Brass & 110.68 & 72.04 & 29 \\
\hline & Strings & 167.74 & 151.53 & 91 \\
\hline & Total & 140.41 & 121.28 & 217 \\
\hline \multirow{4}{*}{ Grade 4} & Piano, keyboard, organ, harp & 347.32 & 335.112 & 28 \\
\hline & Woodwind & 157.73 & 133.21 & 63 \\
\hline & Brass & 141.28 & 100.82 & 42 \\
\hline & Strings & 191.36 & 161.86 & 92 \\
\hline
\end{tabular}




\begin{tabular}{|c|c|c|c|c|}
\hline & Total & 192.00 & 186.49 & 225 \\
\hline \multirow{5}{*}{ Grade 5} & Piano, keyboard, organ, harp & 378.04 & 404.15 & 47 \\
\hline & Woodwind & 161.44 & 142.26 & 125 \\
\hline & Brass & 213.23 & 226.77 & 103 \\
\hline & Strings & 239.52 & 194.28 & 167 \\
\hline & Total & 226.04 & 229.31 & 442 \\
\hline \multirow{5}{*}{ Grade 6} & Piano, keyboard, organ, harp & 334.21 & 369.17 & 19 \\
\hline & Woodwind & 154.98 & 126.61 & 87 \\
\hline & Brass & 214.35 & 188.31 & 53 \\
\hline & Strings & 279.93 & 268.02 & 117 \\
\hline & Total & 231.69 & 233.62 & 276 \\
\hline \multirow{5}{*}{ Grade 7} & Piano, keyboard, organ, harp & 503.25 & 449.87 & 40 \\
\hline & Woodwind & 265.92 & 227.66 & 70 \\
\hline & Brass & 226.78 & 134.43 & 47 \\
\hline & Strings & 312.37 & 243.36 & 98 \\
\hline & Total & 313.79 & 280.59 & 255 \\
\hline \multirow{5}{*}{ Grade 8} & Piano, keyboard, organ, harp & 561.13 & 407.19 & 53 \\
\hline & Woodwind & 363.68 & 379.85 & 76 \\
\hline & Brass & 314.92 & 291.33 & 52 \\
\hline & Strings & 450.60 & 322.89 & 149 \\
\hline & Total & 426.95 & 353.86 & 330 \\
\hline \multirow{5}{*}{ Total } & Piano, keyboard, organ, harp & 328.85 & 362.67 & 339 \\
\hline & Woodwind & 162.49 & 186.41 & 777 \\
\hline & Brass & 196.31 & 196.59 & 400 \\
\hline & Strings & 245.39 & 257.24 & 1043 \\
\hline & Total & 223.60 & 252.62 & 2559 \\
\hline
\end{tabular}


Figure 1: Instrument group differences in weekly practice

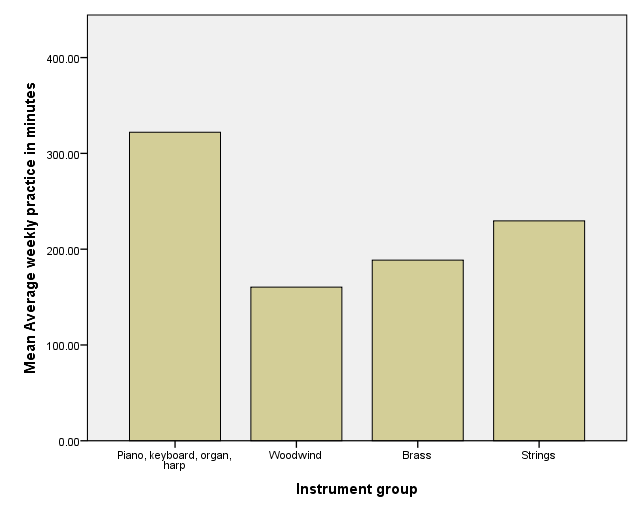

Figure 2: Differences in weekly practice by level of expertise and instrument group

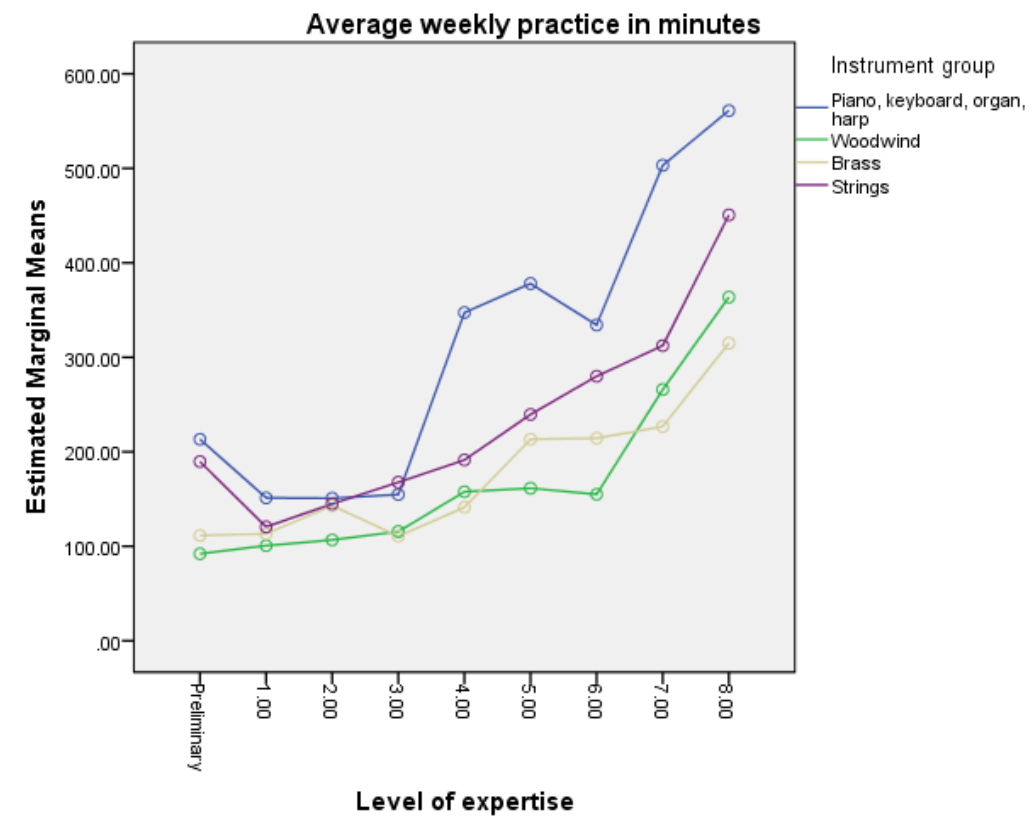

\section{Factor analysis}

To explore the relationships between the variables relating to practice strategies, factor analysis was undertaken. A Principal components analysis was selected as it affords an empirical analysis of the data set (Tabachnick and Fidell, 2001). Eigenvalues were retained if they were greater than 1 and the scree plot was used to identify those factors before the breaking point of the elbow of the plot. A varimax rotation was used to enable interpretation and description of results (Green et al., 2000; Tabachnick and Fidell, 2001). Two checks were 
made to assess sampling adequacy, the Kaiser-Meyer-Olkin (KMO) test (checks whether the sample is large enough to carry out factor analysis) and an anti-matrix of covariances and correlations which showed that all elements on the diagonal of these matrices were greater than -.5 , the necessary requirement. The KMO was 0.86 , greater than the 0.5 required to assess the adequacy of the sample (Field, 2000). Following examination of the scree plot a seven factor solution was deemed to be the most appropriate. Table 3 sets out the weightings. Those below 0.2 have been omitted.

\section{Table 3: Rotated component matrix}




\begin{tabular}{|c|c|c|c|c|c|c|c|}
\hline \multirow[t]{2}{*}{ Statements } & \multicolumn{7}{|c|}{ Factors } \\
\hline & 1 & 2 & 3 & 4 & 5 & 6 & 7 \\
\hline I find it easy to concentrate when I practise & .259 & & & .227 & & .699 & \\
\hline $\begin{array}{l}\text { I try to get an overall idea of a piece before I } \\
\text { practise it }\end{array}$ & & & & .663 & & .251 & \\
\hline $\begin{array}{l}\text { When I practise I only play pieces from } \\
\text { beginning to end without stopping }\end{array}$ & & & & & .701 & & \\
\hline $\begin{array}{l}\text { I work things out just by looking at the music } \\
\text { and not playing }\end{array}$ & & & & .320 & .450 & & \\
\hline $\begin{array}{l}\text { I try to find out what a piece sounds like before } \\
\text { I begin to try to play it }\end{array}$ & & & & .759 & & & \\
\hline $\begin{array}{l}\text { I work out where the difficult sections are } \\
\text { when I'm learning a piece of music }\end{array}$ & .298 & & & .516 & -.229 & & \\
\hline $\begin{array}{l}\text { I practise small sections of the pieces I am } \\
\text { learning }\end{array}$ & .404 & & & .264 & -.405 & & \\
\hline $\begin{array}{l}\text { When I make a mistake, I stop, correct the } \\
\text { wrong note and then carry on }\end{array}$ & .225 & & & & & & .705 \\
\hline $\begin{array}{l}\text { I do warm up exercises at the start of my } \\
\text { practice }\end{array}$ & & .546 & .214 & & & .220 & \\
\hline $\begin{array}{l}\text { I try to get a recording of the piece that I am } \\
\text { learning so that I can listen to it }\end{array}$ & & & .671 & .252 & & & \\
\hline I start my practice with studies & & .444 & .486 & & & & \\
\hline $\begin{array}{l}\text { I analyse the structure of a piece before I learn } \\
\text { to play it }\end{array}$ & & .402 & & .427 & .254 & & \\
\hline I practise things slowly & .649 & & & & & & \\
\hline I know when I have made a mistake & .558 & & & & & .317 & \\
\hline $\begin{array}{l}\text { When I make a mistake I practise the section } \\
\text { where I went wrong slowly }\end{array}$ & .737 & & & & & & \\
\hline $\begin{array}{l}\text { When something is difficult I play it over and } \\
\text { over again }\end{array}$ & .680 & & & & & & \\
\hline $\begin{array}{l}\text { I set myself targets to achieve in each practice } \\
\text { session }\end{array}$ & .371 & .381 & .224 & & .207 & & \\
\hline I am easily distracted when I practise & & & & & & -.773 & \\
\hline $\begin{array}{l}\text { I learn by playing slowly to start with and then } \\
\text { gradually speeding up }\end{array}$ & .585 & .220 & & & & & \\
\hline $\begin{array}{l}\text { When I make a mistake I go back to the } \\
\text { beginning of the piece and start again }\end{array}$ & & & & & .643 & -.247 & \\
\hline $\begin{array}{l}\text { When I'm practising I mark things on the part } \\
\text { to help me }\end{array}$ & .308 & .302 & .228 & & -.305 & & \\
\hline I practise with the metronome & & .224 & .639 & & & & \\
\hline I make a list of what I have to practise & & .621 & & & .208 & & \\
\hline $\begin{array}{l}\text { When I make a mistake I carry on without } \\
\text { correcting it }\end{array}$ & & & & & & & -.793 \\
\hline I start my practice with scales & & .734 & & & & & \\
\hline I record myself playing and listen to the tapes & & & .738 & & & & \\
\hline $\begin{array}{l}\text { I think about how I want to make the music } \\
\text { sound }\end{array}$ & .268 & .204 & .268 & .324 & -.267 & & -.218 \\
\hline
\end{tabular}



Multivariate analysis of variance of the seven practising factors in relation to instrument group differences was highly statistically significant $(\mathrm{F}(8,2418)=4.23, \mathrm{p}=.0001)$.

\section{Factor 1: Adoption of systematic practice strategies}

Factor 1, Adoption of systematic practice strategies had an eigen value of 2.9 accounting for $10.7 \%$ of the variance. This factor had high weightings for practising sections slowly when having made a mistake (.74); practising difficult sections over and over again (.68); slow practice (.65); gradually speeding up when learning fast passages (.59); recognising errors (.56); and practising small sections (.404); There was a significant effect of level of expertise $(F(4,2492)=4.09, p<.0001)$ with a statistically significant linear trend $(F(1,2492)=6.79$, $p<.01)$ indicating that as the level of expertise increased, the adoption of systematic practice strategies increased (see Hallam et al., 2012 for more details). There were no statistically significant differences in instrument group overall but there was an interaction between level of expertise and instrument group $(\mathrm{F}(24)=1.74, \mathrm{p}=.016)$ (see Figure 3). Overall, this showed no clear pattern.

Figure 3: Instrument differences in the adoption of systematic practice strategies by level of expertise 


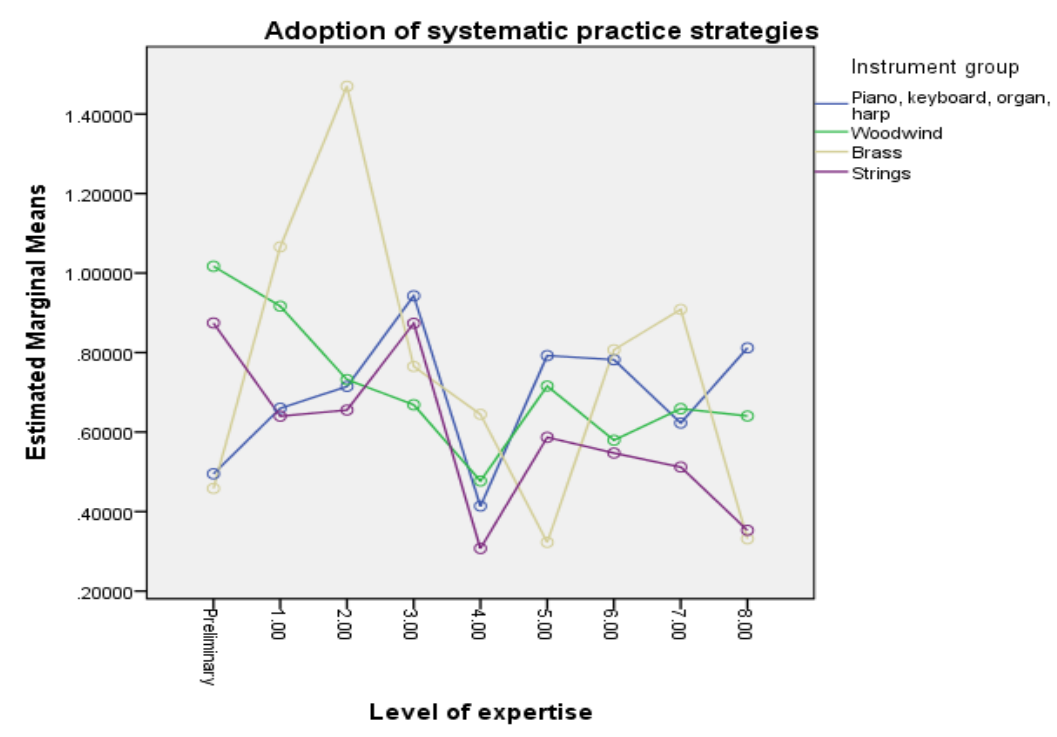

\section{Factor 2: Organisation of practice}

Factor 2: Organisation of practice had an eigen value of 2.073 accounting for $7.7 \%$ of the variance. This factor related to the organisation of practice including starting practice with scales (.73); making a list of what had to be practised (.62); starting with warm up exercises (.55); and starting with studies (.44). There was a significant effect of level of expertise on Factor $2(F=(8,2492) 4.92, p<.0001)$ but no statistically significant linear trend indicating that as level of expertise increased there was no systematic increase in the organisation of practice. There was no statistically significant difference in instrument group in organisation of practice but there was a statistically significant interaction between level of expertise and instrument group $(\mathrm{F}(24)=1.53, \mathrm{p}=.05)$ (see Figure 4). The instrumental groups generally followed a similar pattern with a few exceptions, e.g. brass players' organisation of practice increased at Grade 4, then there was a steep decrease at Grade 5; in string players there was a sharp decrease in the organisation of practice between Grades 3-5 and then there was an increase at Grade 6; in woodwind players there was a steep decrease in the organisation of practice at Grade 7. Apart from these differentiations, the organisation of practice remained relatively stable from early to advanced grades. 
Figure 4: Instrument differences in organisation of practice by level of expertise

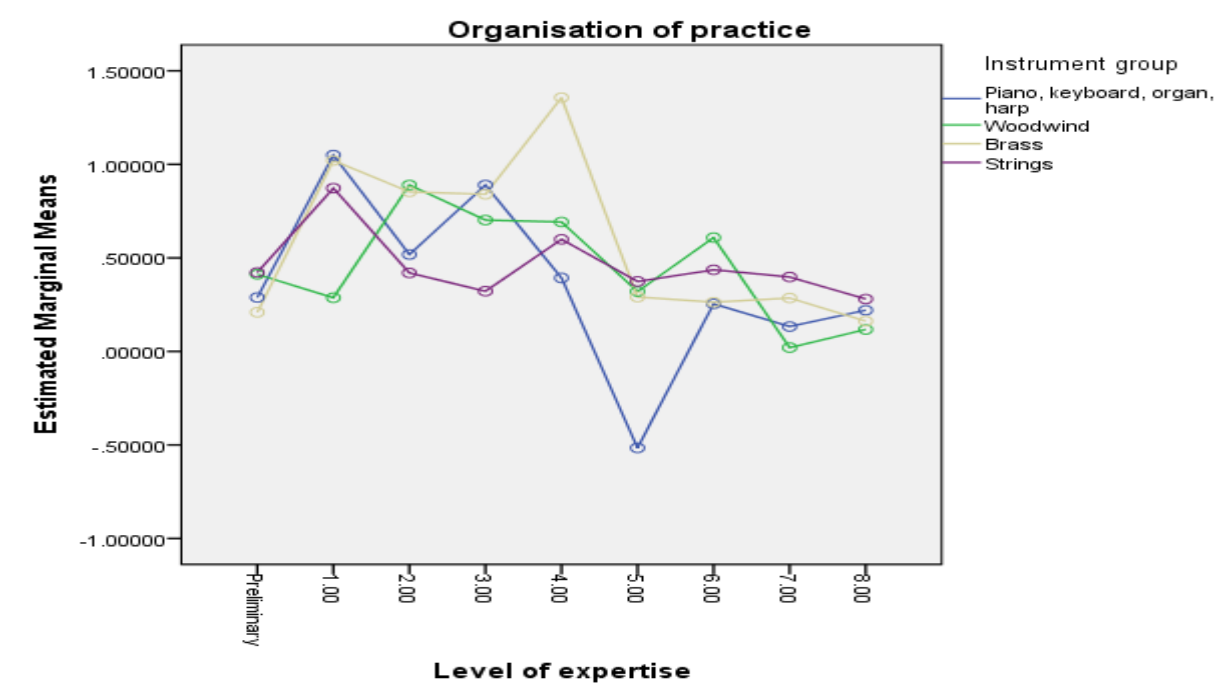

\section{Factor 3: Use of recordings and the metronome}

Factor 3, the use of recordings for listening and feedback and use of metronome had an eigen value of 2.05 accounting for $7.6 \%$ of the variance. It had high weightings for recording selfplaying and listening to the recording (.74); listening to other recordings of the piece to be learnt (.67); and practising with the metronome (.639). There was a significant effect of level of expertise on Factor $3(F=(8,2492) 29.48, \mathrm{p}<.0001)$. There was also a highly statistically significant linear trend $(F(1,2492)=184.5, p<.0001)$ indicating that as expertise increased so did the use of recordings for listening and feedback and use of the metronome. There was a statistically significant instrument difference in the use of recordings and a metronome $(\mathrm{F}(3)=11.89, \mathrm{p}=.0001)$ (see Figures 5 and 6 ) but no statistically significant interaction with level of expertise. The pianists and the string players were more likely to use recordings and a metronome. The woodwind players were the least likely to do so.

Figure 5: Instrument differences in use of recordings and a metronome by level of expertise 


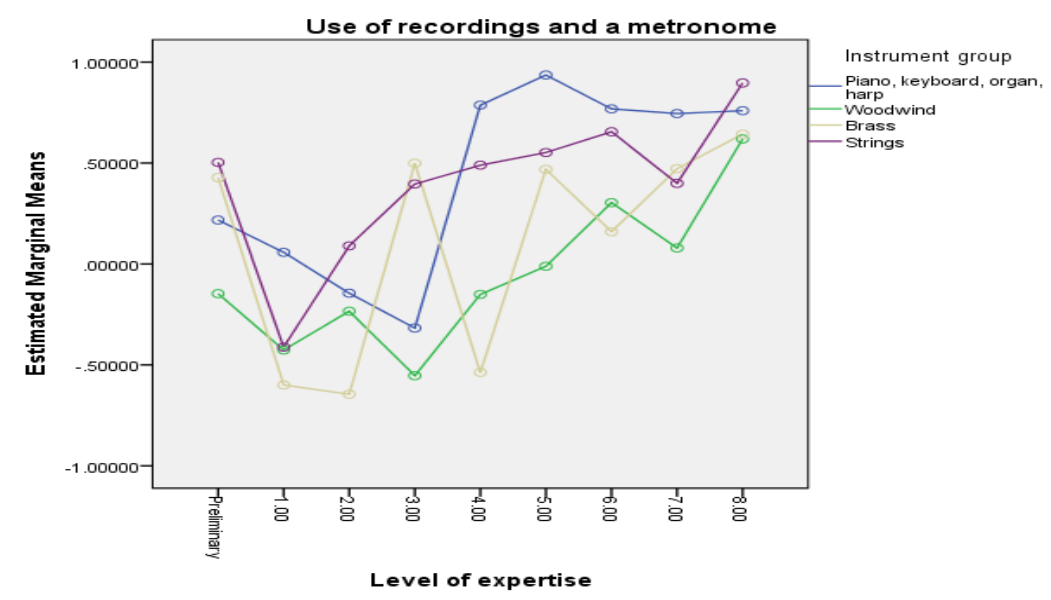

Figure 6: Instrument differences in use of recordings and the metronome

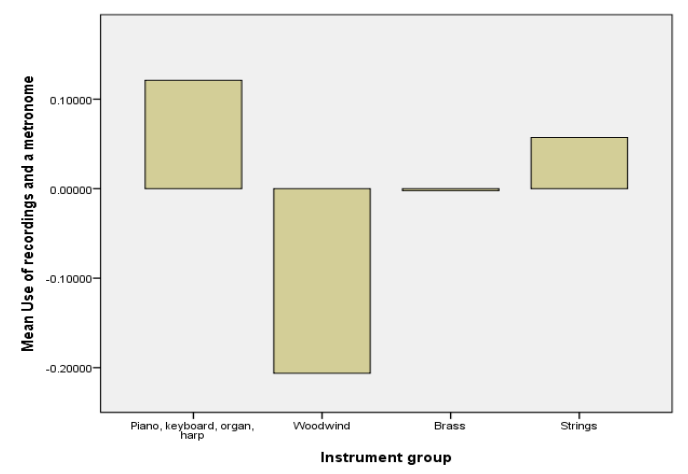

To ascertain which statements in the questionnaire contributed towards these differences analysis of variance was undertaken. There were statistically significant instrument differences in relation to each of the three statements. The woodwind players were the least likely to try to get a recording of the piece that they were learning so that they could listen to it, the string players the most likely. In relation to practising with the metronome, the pianists were most likely to practise with the metronome, the woodwind the least likely. This pattern was the same in relation to recording personal performances (see Table 4).

Table 4: Mean instrument differences in statements relating to use of recordings and the metronome

\begin{tabular}{|l|l|r|r|r|l|}
\hline \multicolumn{2}{|c|}{} & $\mathrm{N}$ & Mean & \multicolumn{1}{|c|}{$\mathrm{SD}$} & \\
\hline \multirow{2}{*}{$\begin{array}{l}\text { I try to get a recording } \\
\text { of the piece that I am }\end{array}$} & Piano, keyboard, organ, harp & 360 & 3.95 & 1.8 & $\mathrm{~F}(3,2893)=10.08$, \\
\cline { 2 - 5 } & Woodwind & 877 & 3.74 & 1.61 & $\mathrm{p}=.0001$ \\
\cline { 2 - 5 } & Brass & 438 & 4.01 & 1.63 & \\
\hline
\end{tabular}




\begin{tabular}{|c|c|c|c|c|c|}
\hline \multirow{2}{*}{$\begin{array}{l}\text { learning so that I can } \\
\text { listen to it }\end{array}$} & Strings & 1222 & 4.15 & 1.73 & \\
\hline & Total & 2897 & 3.98 & 1.69 & \\
\hline \multirow{5}{*}{$\begin{array}{l}\text { I practise with the } \\
\text { metronome }\end{array}$} & Piano, keyboard, organ, harp & 358 & 3.84 & 1.78 & \multirow{5}{*}{$\begin{array}{l}\mathrm{F}(3,2850)=4.44 \\
\mathrm{p}=.004\end{array}$} \\
\hline & Woodwind & 866 & 3.45 & 1.69 & \\
\hline & Brass & 433 & 3.56 & 1.68 & \\
\hline & Strings & 1197 & 3.52 & 1.73 & \\
\hline & Total & 2854 & 3.54 & 1.72 & \\
\hline \multirow{5}{*}{$\begin{array}{l}\text { I record myself } \\
\text { playing and listen to } \\
\text { the tapes }\end{array}$} & Piano, keyboard, organ, harp & 359 & 3.29 & 1.74 & \multirow{5}{*}{$\begin{array}{l}F(3,2859)=16.51 \\
p=.0001\end{array}$} \\
\hline & Woodwind & 869 & 2.61 & 1.61 & \\
\hline & Brass & 433 & 2.79 & 1.66 & \\
\hline & Strings & 1202 & 2.99 & 1.73 & \\
\hline & Total & 2863 & 2.88 & 1.69 & \\
\hline
\end{tabular}

\section{Factor 4: Use of analytic strategies}

Factor 4 , the use of analytic strategies had an eigen value of 1.98 accounting for $7.3 \%$ of the variance. The factor had high weightings for: trying to find out what a piece sounds like before trying to play it (.76); getting an overall idea of a piece before practising it (.66); identifying difficult sections (.52); and analysing the structure of a piece before playing it (.43). There was a significant effect of level of expertise on Factor $4(F(8,2492)=3.249, p<$ .001) but no statistically significant linear trend indicating that as level of expertise increased there was no systematic increase in the use of analytic strategies. There were no statistically significant instrument differences nor an interaction between instrument played and level of expertise, indicating a similar trend across instrument groups as expertise level increased (see Figure 7).

Figure 7: Instrumental differences in use of analytic strategies by level of expertise 


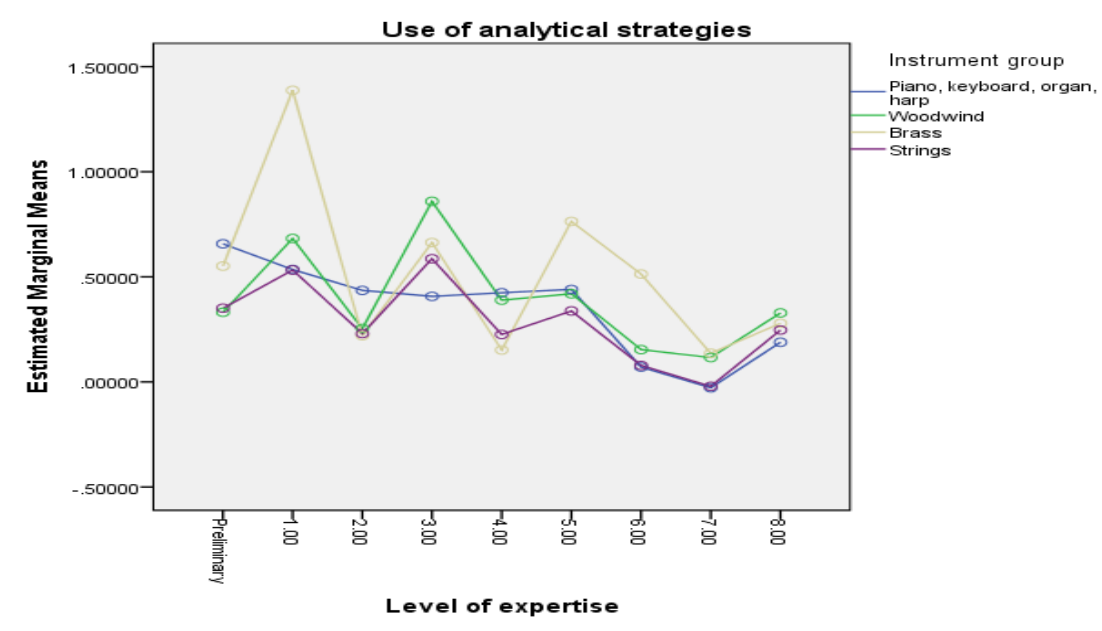

\section{Factor 5: Ineffective practice strategies}

Factor 5, the adoption of ineffective practising strategies had an eigen value of 1.87 accounting for $6.9 \%$ of the variance. There were high loadings on only playing pieces from beginning to end without stopping when practising (.7); and going back to the beginning and starting again when making a mistake (.64). There was a smaller loading on working things out just by looking at the music and not playing (.45). This latter might be conceptualised as a useful strategy, for instance, in terms of mental rehearsal. However, in previous research it was consistently adopted by beginners who also tended to repeat the whole piece with no identification of difficult passages and returned to the beginning of a piece when a mistake was made. For this reason the factor was conceptualised as referring to ineffective practising strategies. This is supported by the negative loadings on identifying difficult sections (-.22); thinking about interpretation (-.27); marking things on the part (-30); and practising small sections (-.40). There was a significant effect of expertise on Factor $5(F(8,2492)=75.72, p$ $<.0001)$ and a highly statistically significant linear trend $(F(1,2492)=462.3, p=.0001)$ indicating that as level of expertise increased there was a decrease in the adoption of ineffective practising strategies. There were statistically significant instrument differences in the adoption of ineffective practising strategies $(\mathrm{F}(3)=3.62, \mathrm{p}=.013)$ and a statistically significant interaction between instrument played and level of expertise $(F(24)=2.03, p=$ 
.002) (see Figures 8 and 9). The brass players were the least likely to adopt ineffective practice strategies, the woodwind players the most likely to.

\section{Figure 8 Adoption of ineffective practising strategies}

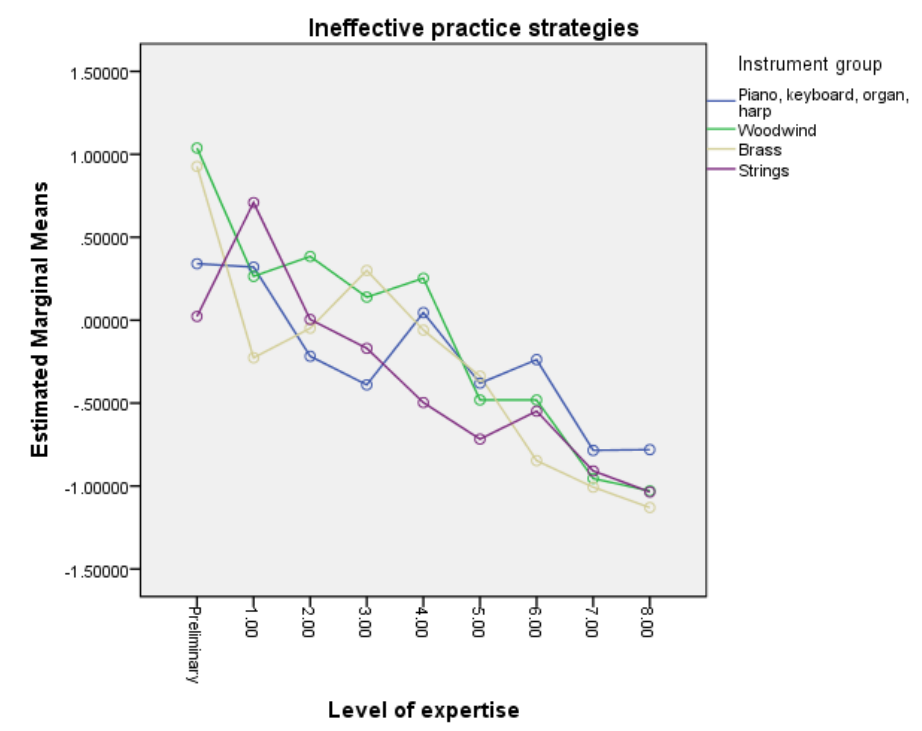

Figure 9: Instrument differences in the adoption of ineffective practising strategies

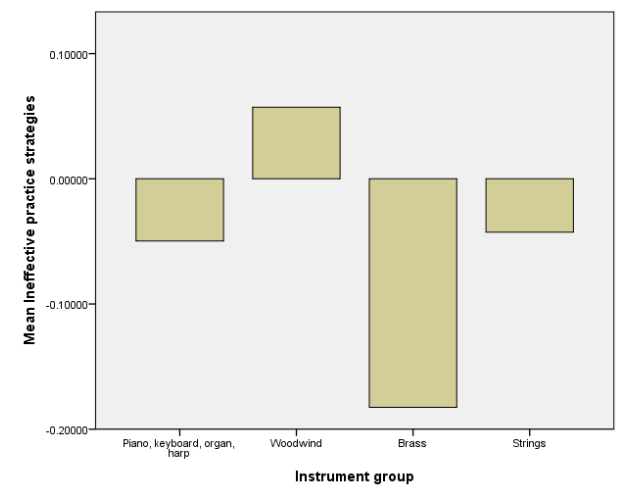

\section{Factor 6: concentration}

Factor 6, concentration had an eigen value of 1.48 accounting for $5.5 \%$ of the variance. The factor had high weightings on finding it easy to concentrate (.69) and negatively on being easily distracted when practising (-.77). There was a significant effect of level of expertise on Factor $6(F(8,2492)=3.218, p<.001)$ but no significant linear trend indicating that as 
expertise increased there was no systematic increase in concentration. There were no statistically significant instrument differences or an interaction with level of expertise, indicating a similar trend between instrument groups in different expertise levels (see Figure 10).

Figure 10: Instrument differences in concentration by level of expertise

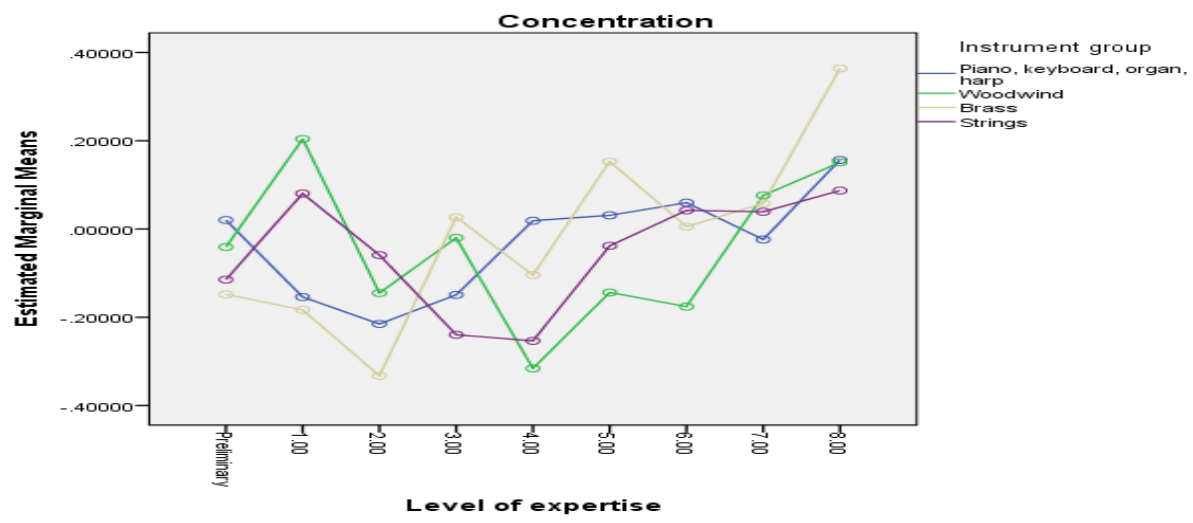

\section{Factor 7: Immediate or non-correction of errors}

Factor 7, immediate or non-correction of errors had an eigen value of 1.34 accounting for $5.0 \%$ of the variance and high weightings in relation to: when making a mistake the wrong note is corrected and then I carry on (.71); and when I make a mistake I carry on without correcting it (-.79). There was a significant effect of level of expertise on Factor $7(F(8,2492)$ $=2.54, p<.01)$ and a statistically significant linear trend $(F(1,2492)=10.482, p<.001)$ indicating that as expertise increased the immediate correction of errors decreased. There was a statistically significant instrument difference in immediate and non-correction of errors $(\mathrm{F}(3)=9.65, \mathrm{p}=.0001)$ and a statistically significant interaction with level of expertise $(\mathrm{F}(24)=3.18, \mathrm{p}=.0001)$ (see Figures 11 and 12). The brass players were the least likely to either immediately correct or not correct errors, particularly in the early stages of learning to play followed by the keyboard players. The most likely group to adopt strategies of immediate correction or non-correction of errors were the string players.

\section{Figure 11: Instrument differences in immediate or non-correction of errors}




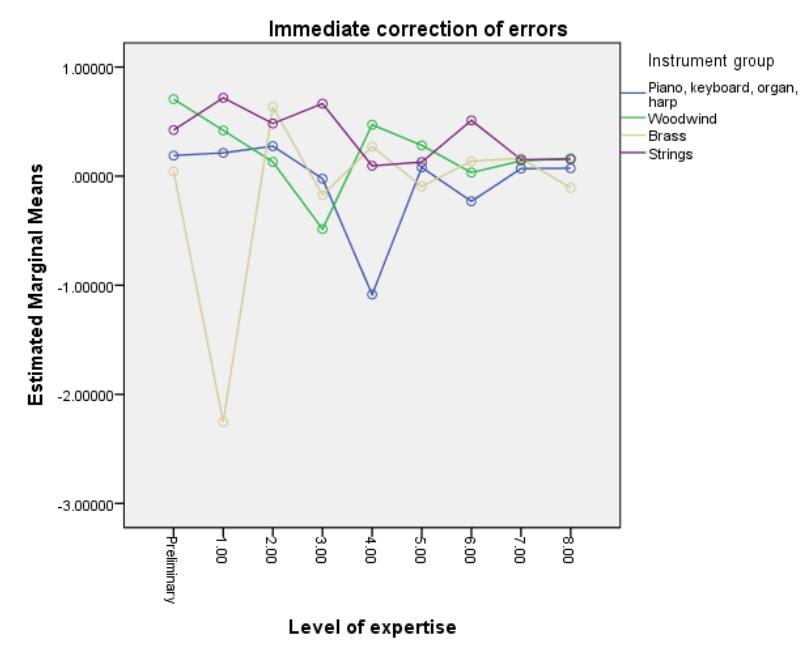

Figure 12: Instrument differences in immediate or non-correction of errors by level of expertise

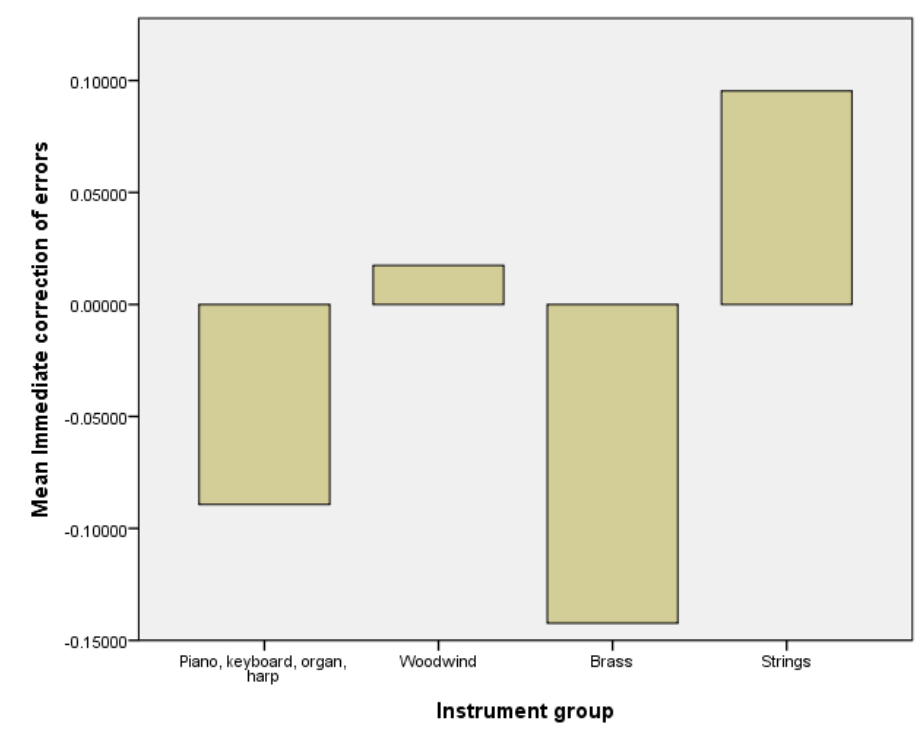

\section{Attitude towards practising}

In addition to data on practising strategies and organisation of practice participants were asked to indicate their agreement to statements related to liking practice. The means for the statements relating to liking practice were 4.7 for 'I like practising' (range 4.9 to 4.4 ); 5.2 for 'On some days I don't want to practise' (range 4.7 to 5.4); and 3.5 for 'I find practice boring' (range 3.3 to 3.9). There was no significant effect of level of expertise on liking practice or 
finding practice boring, although there was a significant linear trend in relation to not wanting to practise on some days $(F(1,2805)=9.67, p<.0001)$ indicating that as expertise increased so did reluctance to practise on some days. A principal components factor analysis was undertaken with varimax rotation on the variables related to attitude towards practising. The KMO was 0.58 , greater than the 0.5 required to assess the adequacy of the sample (Field, 2000). Following examination of the scree plot a single factor solution was deemed to be the most appropriate. The weightings for the variables were 'I like practising' -.743; 'On some days I don't want to practise' .623; and 'I find practising boring' .808. The factor focus is on disliking practice. Table 5 sets out the mean factor scores by level of expertise. There was a significant effect of level of expertise on attitude to practice $(F(8,942)=3.8, p<.0001)$ and a statistically significant linear trend $(F(1,942)=12.5, p<.0001)$ indicating that as expertise increased enjoyment of practice decreased. There was no statistically significant instrument difference but there was a statistically significant interaction with level of expertise $(\mathrm{F}(24)=$ $1.54, \mathrm{p}=.049$ ) (see Figure 13). There was a similar trend in the instrument groups across different levels of expertise with a few exceptions, e.g. string players' dislike of practice increased between Preliminary and Grade 2, and Grades 4-6; in brass players there was a steep increase in Grades 2-3 and then a decrease at Grade 4.

Table 5: Attitude towards practising

\begin{tabular}{|l|l|l|l|l|l|l|l|l|l|l|l|}
\hline Grade & Pre & 1 & 2 & 3 & 4 & 5 & 6 & 7 & 8 & Total & $\begin{array}{l}\text { Linear } \\
\text { sig }\end{array}$ \\
\hline I like practising & 4.9 & 4.9 & 4.7 & 4.4 & 4.4 & 4.6 & 4.5 & 4.8 & 4.9 & 4.7 & NS \\
\hline $\begin{array}{l}\text { On some days I don't want } \\
\text { to practise }\end{array}$ & 4.7 & 5.0 & 5.1 & 5.2 & 5.3 & 5.3 & 5.4 & 5.3 & 5.4 & 5.2 & .0001 \\
\hline I find practising boring & 3.3 & 3.4 & 3.5 & 3.9 & 3.9 & 3.5 & 3.9 & 3.3 & 3.3 & 3.5 & NS \\
\hline
\end{tabular}




\section{Figure 13: Instrument differences in attitude towards practice by level of expertise}

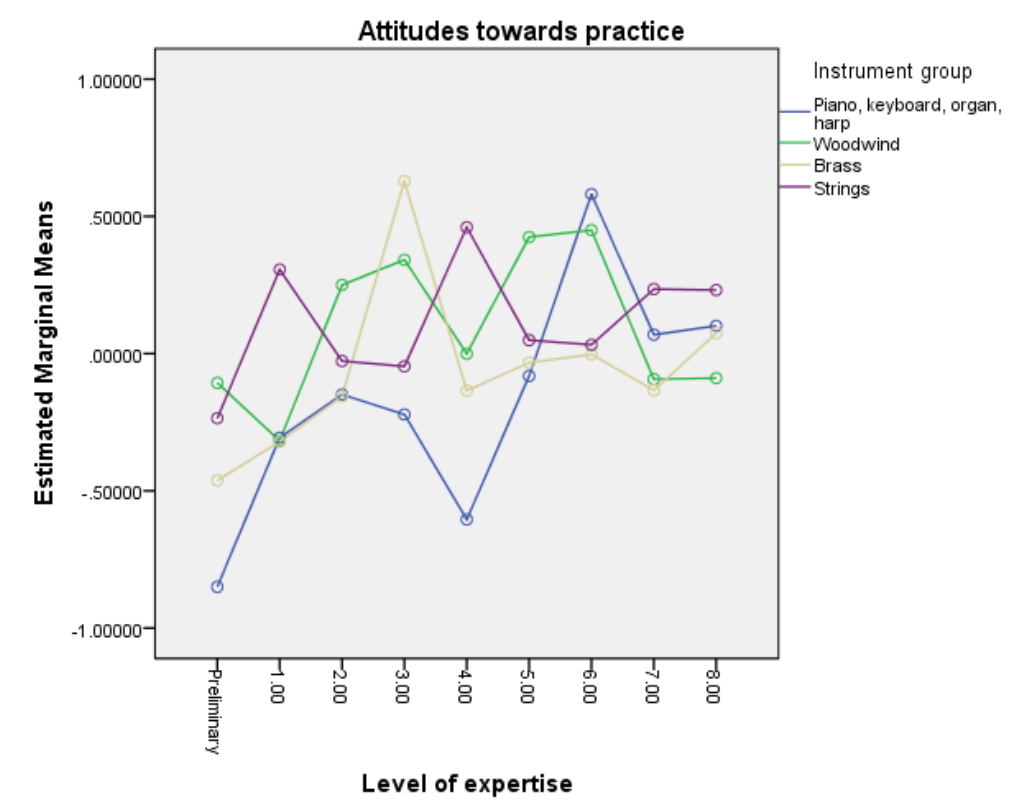

\section{Discussion}

There are clearly limitations to this research. The data were based on self-report. Respondents may have given responses which were not true reflections of the amount of practice that they typically undertook or the strategies which they adopted. Indeed, there is evidence that learners, typically, report the adoption of strategies before they implement them (Flavell, 1976). This may have distorted the findings. Despite these limitations, the findings do provide important insights into the amount of time spent practising and the nature of that practice for those in different instrument groups.

Overall, the amount of practice undertaken increased as learners became more expert. For several instrument groups the amount of practice almost doubled. However, there were wide individual differences. There are several reasons why this might be the case. One explanation is in terms of repertoire. There is a much greater repertoire for the piano than for other 
instruments. However, the sample in this study were still of school age, most would not be pursuing a musical career and therefore the extensive piano repertoire is unlikely to have impacted on their practice time. However, the difficulty of the repertoire might be important. Reading from two staves and having simultaneously to play two hands together when each is playing independent parts may simply be more challenging cognitively than playing the repertoire for other instruments and therefore may take longer to learn leading to more practice. Another possibility is that the physical stress of playing the piano is less than for other instruments. This may mean that pianists do not tire physically as quickly as other instrumentalists and therefore can carry on for longer. Certainly, the least practice was undertaken by the woodwind and brass players whose facial muscles are placed under considerable strain when practising. Another possible explanation is that music played on the piano provides a complete musical experience including melodic and harmonic elements, whereas most other instruments require accompaniment to provide a harmonic basis. Pianists may therefore derive more musical satisfaction from practice, although the data relating to attitudes towards practice does not support this. In addition, the piano provides easy physical access in comparison with other instruments. It is easy to play for a few moments as no prior instrument preparation is needed. Of course, it is possible that piano teachers set more work than teachers of other instruments. Further research will be required to establish if this is the case.

The findings relating to attitudes towards practice reflect previous research suggesting that young musicians, like professionals, are ambivalent about practising. While responses to enjoying practice were broadly positive, respondents indicated that they did not feel like practising every day, and that practising could be boring. There are implications here for teaching. Teachers need to consider how they can make practice more interesting. One 
possibility is to offer learners some choice in the repertoire that is learned (see McPherson, 2005). This is likely to enhance motivation to practise. Teaching pupils how to practice effectively may also make practice more rewarding. Encouraging learners to join musical groups can also provide opportunities for enhancing technical skills in an environment that can be musically and socially rewarding.

Overall, there were relatively few statistically significant differences between the instrument groups in relation to the practising strategies adopted, although there were a number of interactions between instrument group and level of expertise. In most cases where there were interactions no clear pattern emerged, although the brass players were more likely to adopt systematic practice strategies and least likely to immediately or not correct errors in the early stages of learning. In addition, overall, they were also the least likely to adopt ineffective practice strategies. There were statistically significant differences in relation to the use of the metronome and recordings. Analysis of each of the statements included in the factor separately showed that these differences were in evidence in relation to teach statement. Overall, the least likely to adopt any of these strategies were the woodwind players. Overall, the woodwind players did the least practice and were less likely to adopt the most effective ways of practising. It is unlikely that these differences can be explained in relation to repertoire or even the demands of the instrument as some of these strategies were not directly connected to the instrument per se, for instance using the metronome, recording themselves playing. It might be that woodwind players start learning at a later age than other instrumentalists and have less direct parental supervision of practice which means that they do not learn effective strategies so quickly. In terms of the amount of practice undertaken they also reflect the findings of Jørgensen (2002) and Lammer and Kruger (2006). 
Overall, the findings presented here raise many questions. Some of these may be resolved by further analysis of the data within the instrument groups (e.g. popular and classical) and families (e.g. trumpet, French horn, trombone, tuba). However, some issues need to be explored further adopting qualitative or observational data of actual practice, while others require information from teachers (e.g. expectations about practice time, its content and repertoire) and parents (e.g. the extent to which they supervise or support practice).

\section{References}

Field, A. (2000) Discovering statistics using SPSS for Windows. London, thousand Oaks. New Dehli: Sage.

Flavell, J. H. (1976). 'Metacognitive aspects of problem solving'. In L. B. Resnick (Ed.), The nature of intelligence (pp. 231-235). New Jersey: Erlbaum.

Green, S.B. Salkind, N.J. \& Akey, T.M. (2000) Using SPSS for windows: Analysing and Understanding data (Second Edition) New Jersey: Prentice-Hall.

Hallam, S. (2013) What predicts level of expertise attained, quality of performance, and future musical aspirations in young instrumental players? Psychology of Music, 41(3), 265-289.

Hallam, S. Rinta, T. Varvarigou, M., Creech, A. Papageorgi, I., and Lani, J. (2012) The development of practising strategies in young people, Psychology of Music, 40(5), 652-680.

Jørgensen, H. (1997) Time for practising? Higher level music students' use of time for instrumental practising In In: H. Jørgensen and A. C. Lehman (Eds), "Does practice make perfect? Current theory and research on instrumental music practice”, Norges musikkhogskole, Oslo (pp 123-140).

Jørgensen, H. (2002) 'Instrumental performance expertise and amount of practice among instrumental students in a conservatoire'. Music Education Research, 4, 105-119.

Jørgensen, H. \& Hallam, S. (2016) Practising In S. Hallam, I. Cross, I. \& M Thaut (eds) Oxford Handbook of Music Psychology $2^{\text {nd }}$ edition Oxford: Oxford University Press (pp 449-462).

Lammers, M. \& Kruger, M. (2006) Brass and Woodwind Student Practice Habits in Norway, Japan, and the United States. NACWAPI (National Association of Wind and Percussion Instructors) Journal, Summer 2006, 54(4), 4-13.

McPherson, G. E. (2005). 'From child to musician: skill development during the beginning stages of learning an instrument'. Psychology of Music, 33, 1, 5-35. 
Rubin-Rabson, G. (1940) Studies in the psychology of memorizing piano music: II. A comparison of massed and distributed practice. Journal of Educational Psychology, 31(4), Apr 1940, 270-284.

Rubin-Rabson, G. (1941) Studies in the psychology of memorizing piano music. VII. A comparison of three degrees of overlearning. Journal of Educational Psychology, 32(9), Dec 1941, 688-696.

Tabachnick, B.G. \& Fidell, L.S. (2001) Using multivariate statistics (Fourth Edication). Boston: allyn and Bacon, Pearson International. 


\section{Appendix}

\section{Research on instrumental practising}

We are conducting some research on instrumental practising. We would be very grateful if you would complete this questionnaire. It will take you about 10 minutes. Thank you for your time.

Name

Age

Main instrument

Other instruments

Do you take part in musical groups at school, e.g. orchestra, band? Yes/No

If yes, please indicate what the groups are

Do you take part in musical groups out of school, e.g. county groups, community groups? Yes/No

If yes, please indicate what the groups are

On average how many days a week do you practise?

On average, how much practice do you do on each day?

How long have you been learning your first instrument? years months

What is the most recent grade examination you have taken?

What mark did you get? (please include the maximum that you could have attained, e.g. $71 / 100$ or $121 / 150$

Please indicate in the table below how strongly you agree or disagree with the following statements. Please answer ONLY in relation to your main instrument.

\begin{tabular}{|l|l|l|l|l|l|l|l|}
\hline & $\begin{array}{l}\text { Very } \\
\text { strongly } \\
\text { agree }\end{array}$ & $\begin{array}{l}\text { Strongly } \\
\text { agree }\end{array}$ & Agree & Neutral & Disagree & $\begin{array}{l}\text { Strongly } \\
\text { disagree }\end{array}$ & $\begin{array}{l}\text { Very } \\
\text { strongly } \\
\text { disagree }\end{array}$ \\
\hline Practising strategies & & & & & & & \\
\hline $\begin{array}{l}\text { I try to get an overall idea of a piece } \\
\text { before I practise it }\end{array}$ & & & & & & & \\
\hline $\begin{array}{l}\text { When I practise I only play pieces } \\
\text { from beginning to end without } \\
\text { stopping }\end{array}$ & & & & & & & \\
\hline $\begin{array}{l}\text { I work things out just by looking at the } \\
\text { music and not playing }\end{array}$ & & & & & & & \\
\hline $\begin{array}{l}\text { I try to find out what a piece sounds } \\
\text { like before I begin to try to play it }\end{array}$ & & & & & & & \\
\hline $\begin{array}{l}\text { I work out where the difficult sections } \\
\text { are when I'm learning a piece of music }\end{array}$ & & & & & & & \\
\hline
\end{tabular}




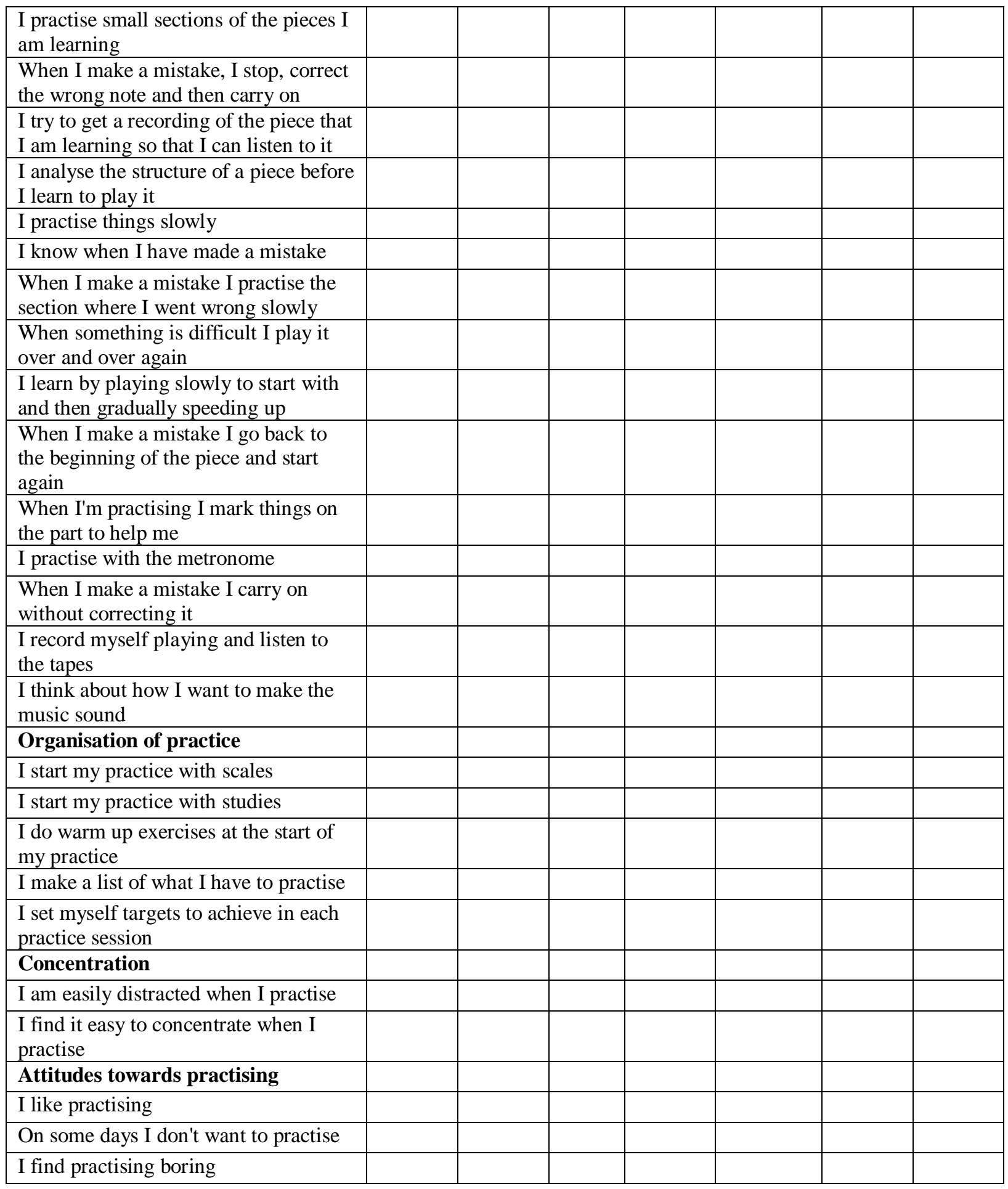

Thank you for completing this questionnaire 